\title{
Integrins and p53 pathways in glioblastoma resistance to temozolomide
}

\section{Sophie Martin, Hana Janouskova and Monique Dontenwill*}

Laboratory of Biophotonics and Pharmacology, UMR 7213 CNRS, Faculté de Pharmacie, Université de Strasbourg, IIIkirch, France

\section{Edited by:}

Gaspar Kitange, Mayo Clinic, USA

Reviewed by:

Hazem J. Abuhusain, University of New South Wales, Australia

Leonora Balaj, Massachusetts General

Hospital, USA

Brenda Auffinger, University of

Chicago, USA

\section{${ }^{*}$ Correspondence:}

Monique Dontenwill, Laboratory of

Biophotonics and Pharmacology,

UMR 7213 CNRS, Faculté de

Pharmacie, Université de

Strasbourg, 74 Route du Rhin,

67401 IIlkirch, France.

e-mail:monique.dontenwill@unistra.fr
Glioblastoma is the most common malignant primary brain tumor. Surgical resection, postoperative radiotherapy plus concomitant and adjuvant chemotherapy with temozolomide (TMZ) is the standard of care for newly diagnosed glioblastoma. In the past decade, efforts have been made to decipher genomic and core pathway alterations to identify clinically relevant glioblastoma subtypes. Based on these studies and more academic explorations, new potential therapeutic targets were found and several targeting agents were developed. Such molecules should hopefully overcome the resistance of glioblastoma to the current therapy. One of the hallmarks of glioblastoma subtypes was the enrichment of extracellular matrix/invasion-related genes. Integrins, which are cell adhesion molecules important in glioma cell migration/invasion and angiogenesis were one of those genes. Integrins seem to be pertinent therapeutic targets and antagonists recently reached the clinic. Although the p53 pathway appears often altered in glioblastoma, conflicting results can be found in the literature about the clinically relevant impact of the p53 status in the resistance to TMZ. Here, we will summarize the current knowledge on (1) integrin expression, (2) p53 status, and (3) relationship between integrins and p53 to discuss their potential impact on the resistance of glioblastoma to temozolomide.

Keywords: integrin, p53, temozolomide, glioblastoma, chemoresistance

\section{INTRODUCTION}

Glioblastoma is characterized by rapidly dividing cells, high degree of vascularity, invasion into the normal brain tissue, and an intense resistance to death-inducing stimuli. Significant advances have been made in understanding the molecular genetics underlying the heterogeneity of glioblastoma and their resistance to therapies. However, standard therapy including surgical resection and radiotherapy with concomitant and adjuvant chemotherapy using temozolomide (TMZ) remains poorly efficient (Stupp et al., 2005). Prognostic and predictive markers are continuously proposed based on large scale genomic data. In the recent years, emphasis has been given to the predictive impact of $\mathrm{O}^{6}$-methylguanine-DNA methyltransferase (MGMT) expression/activity, a DNA repair enzyme that protects cells against alkylating drugs such as TMZ (Stupp et al., 2009). The promoter of the MGMT gene is methylated in $40-45 \%$ of glioblastoma and the enzyme is not expressed in the majority of these cases (Hegi et al., 2005; Silber et al., 2012). While the contribution of MGMT to TMZ resistance is highly documented, tumors in which MGMT is not the primary determinant of treatment outcome also exist (Carlson et al., 2009; Combs et al., 2011). Integrins have been proposed to play a role in the aggressiveness of gliomas and have been implicated in radio/chemoresistance in different types of tumors (Aoudjit and Vuori, 2012). The p53 protein has been largely studied in gliomas but its prognostic value has not been consistently established. In line with our recent data proposing an $\alpha_{5} \beta_{1}$ integrin-p53 axis with potential implication in TMZ resistance (Janouskova et al., 2012), we will summarize here the current knowledge on integrins and p53 status in glioblastoma.

\section{INTEGRINS IN GLIOMA}

\section{BIOLOGY OF INTEGRINS}

Integrins are heterodimeric cell surface receptors that mediate cell adhesion to the extracellular matrix (ECM) and support cell-cell interactions in a multitude of physiological and pathological situations. They are at least 24 known $\alpha \beta$ heterodimers formed by a combination of $18 \alpha$ and $8 \beta$ subunits bound non-covalently. Natural ligands of integrins are component of the ECM such as vitronectin, collagen, or fibronectin. Each $\alpha \beta$ integrin pair has a defined set of ECM protein (Hynes, 2002). The repertoire of integrins present at the membrane dictates therefore the extent to which a cell will behave on a specific matrix and respond to its environment. Once engaged with the ECM, integrins cluster and recruit various signaling and adaptor proteins to form focal adhesion complexes (Geiger et al., 2001). These complexes activate intracellular downstream signaling pathways including NF-кB, PI3K, Src, or Ras-MAP kinases (Hynes, 2002; Legate et al., 2009). Such pathways regulate functions involved in motility, cytoskeleton organization, adhesion, proliferation, survival, and gene transcription. Integrins link ECM to the actin cytoskeleton through FAK/ILK/SFK/Rho proteins pathway providing the traction necessary for cell motility (Geiger et al., 2001). Integrins regulate the localization and the activity of urokinase-type plasminogen activator (uPA)/uPA receptor (Ghosh et al., 2000; Wei et al., 2007; Bass and Ellis, 2009) and matrix metalloproteinases (MMPs; Lamar et al., 2008; Morozevich et al., 2009) therefore controlling ECM remodeling and the invasive process.

Beside their mechanical functions and despite the lack of intrinsic kinase activity, integrins are true signaling molecules. 
Integrins regulate proliferation by controlling the expression of cyclin D1 which permits cells to enter the S-phase of the cell cycle (Fournier etal., 2008). Integrins relay survival or apoptotic signals depending on the surrounding environment. Integrin ligation promote survival through various mechanisms including increased anti-apoptotic proteins (bcl-2, FLIP; Aoudjit and Vuori, 2001b; Matter and Ruoslahti, 2001; Uhm et al., 1999), activation of PI3K-Akt (Aoudjit and Vuori, 2001a) or NF- $\mathrm{B}$ pathway (Scatena and Giachelli, 2002; Courter et al., 2005). Unligated integrins were reported to promote apoptosis through the so-called integrin-mediated death (IMD) a mechanism dependent, or not, on caspases activation in anchorage-dependent cells (Stupack etal., 2001; Jan etal., 2004). However, tumor cells are often IMD-resistant and unligated integrins rather promote anchorage-independent growth, survival, and metastasis than apoptosis (Desgrosellier et al., 2009). Additionally, crosstalks occur between integrins, cytokines, and growth factor receptors. Optimal growth factor stimulation relies on integrinmediated adhesion to an appropriate ECM protein. $\alpha_{V} \beta_{3 / 5}$ and $\alpha_{5} \beta_{1}$ interact with growth factor receptors (VEGFR2, c-Met, FGFR1, PDGFR, EGFR, TIE-2, and IGF-1R) to promote full activation of each receptor and maximal signal transduction (increased MAPK and Akt activity) resulting in enhanced cell migration, proliferation, survival, and angiogenesis (Friedlander et al., 1995; Eliceiri, 2001; Alam et al., 2007; Soung et al., 2010). Integrins were also reported to bind directly growth factor (such as angiopoietins or VEGF) allowing the transduction of information in the absence of the receptor (Carlson et al., 2001; Hutchings et al., 2003). In short, integrins sense, interpret, and distribute information so that cancer cells adjust and respond to their microenvironment.

\section{INTEGRIN EXPRESSION AND FUNCTION IN GLIOMA}

Clustering of transcriptomic data from high grade glioma predicted poor survival in subclasses of tumors overexpressing ECM components such as fibronectin which is the preferred ligand of $\alpha_{5} \beta_{1}$ and $\alpha_{v} \beta_{3}$ integrins (Geiger et al., 2001; Freije et al., 2004; Bredel et al., 2005; Colin et al., 2006; Tso et al., 2006). Functional analysis revealed gliomagenesis and glioblastoma networks composed of genes that play a role in integrin signaling including fibronectin, $\alpha_{3}$ and $\alpha_{5}$ integrins (Bredel et al., 2005). Gingras et al. (1995) investigated glioblastoma for the expression of cell adhesion molecules including integrins that might distinguish tumor from normal adjacent brain tissue. Results showed that glioblastoma expressed $\alpha_{2}, \alpha_{3}, \alpha_{5}, \alpha_{6} \beta_{1}$, and $\alpha_{v} \beta_{3}$ integrins at significantly higher level than normal brain tissue suggesting that these integrins might play a role in the development or the progression of glioma (Gingras et al., 1995). $\beta_{8}$ and $\alpha_{5} \beta_{1}$ integrins were commonly expressed in a perinecrotic or perivascular pattern in glioblastoma (Riemenschneider et al., 2005). Higher levels of $\alpha_{5}$ and $\beta_{3}$ integrin mRNA were measured in glioblastoma as compared to normal brain or low grade astrocytoma (Kita et al., 2001). Average $\alpha_{v} \beta_{3}$ integrin expression in glioblastoma seemed to exceed those in low grade glioma at the protein level although mRNA levels of both subunits were not discriminative between glioblastoma and low grade glioma (Schnell et al., 2008). In another study, $\alpha_{v} \beta_{5}$ and $\alpha_{5} \beta_{1}$ integrins were shown to be expressed at consistently higher levels than $\alpha_{V} \beta_{3}$ integrins in human glioma cell explants (Mattern et al., 2005). We and others showed recently that $\alpha_{5} \beta_{1}$ integrin expression in biopsies from patient with glioma correlated with poor prognosis and tumor aggressiveness (Cosset et al., 2012; Holmes et al., 2012; Janouskova et al., 2012).

In glioma, integrins were often studied because of their crucial role in tumor cell invasion (Gritsenko et al., 2012). Both $\beta_{1}$ subunit-containing integrins (Paulus et al., 1996) and $\alpha_{V} \beta_{3}$ integrins control glioma cell invasion (D'Abaco and Kaye, 2007). $\alpha_{2} \beta_{1}$, $\alpha_{3} \beta_{1}$, and $\alpha_{5} \beta_{1}$ integrins are overexpressed in multidrug-resistant glioma cells and are responsible for their increased adhesive and invasive capacities (Hikawa et al., 2000). The laminin-5 receptor $\alpha_{3} \beta_{1}$ integrin is mainly expressed in areas of tumor cell invasion and support glioma cell migration and invasion (Tysnes et al., 1996; Mahesparan et al., 2003; Kawataki et al., 2007). $\alpha_{V} \beta_{3}$ integrins promote migration and adhesion in various glioma cells (Gladson and Cheresh, 1991; Friedlander et al., 1996) and inhibition of $\alpha_{\mathrm{v}} \beta_{3}$ integrin with neutralizing antibody inhibited migration and invasion selectively in cell lines that contained a high level of integrin expression (Wild-Bode et al., 2001). Our laboratory extensively investigated $\alpha_{5} \beta_{1}$ integrins in glioma. We showed that $\alpha_{5} \beta_{1}$ integrins increased proliferation, clonogenic survival, adhesion, migration, and invasion of various glioma cell lines (Maglott etal., 2006; Bartik et al., 2008; Martin et al., 2009; Cosset et al., 2012). We also reported that the expression of $\alpha_{5} \beta_{1}$ integrins in glioma is controlled by caveolin-1 (Martin et al., 2009; Cosset et al., 2012). Interestingly, it was shown recently that invasive recurrent glioblastoma, resistant to antiangiogenic therapy, overexpress $\alpha_{5} \beta_{1}$ integrin and its ligand fibronectin (DeLay et al., 2012). $\alpha_{V} \beta_{3}$ integrin/ILK/RhoB pathway (Monferran et al., 2008) and $\beta_{1}$ integrin/AKT/p130Cas/paxillin (Cordes et al., 2006) controlled the radiosensitivity of glioma cells by regulating radiation-induced cell death. Recruitment of $\alpha_{v} \beta_{3 / 5}$ integrin in glioblastoma cells is induced by hypoxia. It follows the activation of FAK/RhoB/GSK3 $\beta$ pathway leading to HIF-1 $\alpha$ induction and the transcription of proangiogenic factors (Skuli et al., 2009). Finally, surface expression of $\alpha_{6} \beta_{1}$ integrin in U87MG cells enhanced cell spreading and attachment on laminin-111, increased proliferation, decreased apoptosis due to serum starvation and increased migration and invasion of U87MG cells both in vitro and in vivo (Delamarre et al., 2009).

\section{INTEGRINS IN GLIOMA ANGIOGENESIS}

Induction of angiogenesis is essential for a tumor to grow beyond 1-2 $\mathrm{mm}$ and glioblastoma exhibit prolific angiogenesis. Poorly expressed in resting endothelial cells, $\alpha_{5} \beta_{1}$ and $\alpha_{v} \beta_{3 / 5}$ integrins are highly upregulated on endothelium cells during tumor angiogenesis (Bussolati et al., 2003; Avraamides et al., 2008; Desgrosellier and Cheresh, 2010) and rapidly accessible in tumor blood vessels (Magnussen et al., 2005). They stimulate endothelial cell proliferation, promote migration, and lumen formation (Mettouchi and Meneguzzi, 2006). Although $\alpha_{5} \beta_{1}$ integrin is undoubtedly recognized as a proangiogenic factor, controversial results for $\alpha v \beta 3$ integrin questioned its role (Hodivala-Dilke, 2008; Robinson and Hodivala-Dilke, 2011). Overexpression of $\alpha_{v} \beta_{3}$ integrin in glioma exerted growth-suppressive effects in vivo that are linked 
to vascular defects (Reynolds et al., 2002; Kanamori et al., 2004, 2006). However, antagonists to both $\alpha_{5} \beta_{1}$ and $\alpha_{\mathrm{V}} \beta_{3 / 5}$ integrins are able to inhibit tumor angiogenesis (Brooks et al., 1995; Friedlander et al., 1995; Kim et al., 2000).

\section{INTEGRINS IN GLIOMA STEM CELLS}

Brain tumors also contain highly tumorigenic and therapeutically resistant pluripotent stem cells referred as glioma stem or initiating cells. The glioma stem cell hypothesis incorporates a model in which only a small subset of cells, the glioma stem cells, can initiate tumor. This hypothesis was confirmed very recently in vivo (Lathia et al., 2011). Elevated levels of $\alpha_{6} \beta_{1}$ integrins were found in glioma stem cells and seem to be a reliable new marker to enrich for glioma stem cells (Lathia et al., 2010).

Integrins are implicated at various levels of glioma development and progression. Blocking their functions may affect both tumoral cells and endothelial cells and these characteristics made them attractive therapeutic targets for glioblastoma (Chamberlain et al., 2012; Goodman and Picard, 2012). Emphasis on $\alpha_{v} \beta_{3}$ integrins has been given recently as cilengitide, their prototypical small peptide antagonist, is currently evaluated in phase III clinical trials in glioblastoma (Tabatabai et al., 2010). Interestingly, the outcome in a phase II trial was particularly good in patients with a methylated MGMT gene promoter (Stupp et al., 2010). Emerging data showing the role of $\alpha_{5} \beta_{1}$ integrin in glioblastoma give some hope for new therapeutic propositions in the near future.

\section{p53 PROTEIN IN GLIOMA}

p53, the "guardian of the genome," is certainly one of the most widely studied protein in human glioma. Activation of the tumor suppressor p53 by stress signals triggers different cellular programs such as cell cycle arrest, apoptosis, differentiation, DNA repair, autophagy, and senescence through complex network and signaling pathways (Levine and Oren, 2009; Vousden and Prives, 2009; Sullivan et al., 2012). Gaining a better understanding of how transcriptional and non-transcriptional functions of p53 integrate will be of great importance for the proposal of new therapeutic options (Dai and Gu, 2010; Speidel, 2010). Somatic p53 missense mutations are found in approximately $50 \%$ of all human cancers. Intensive research on p53 status as a classical molecular marker led to controversial results and non-significant clinical impact, particularly in the glioma field.

\section{p53 STATUS IN GLIOMA}

As most mutations in p53 gene led to the accumulation of p53 in the nucleus, nuclear overexpression of p53 was usually considered as a marker of mutation. Several studies showed that the expression of p53 is correlated at $90 \%$ with its mutation (Figarella-Branger et al., 2011). Detection of p53 mutation by the yeast functional assay that measures quantitatively mutant p53 alleles and qualitatively the loss of p53 competence was also employed and compared to conventional techniques including DNA sequencing (Tada et al., 1997; Fulci et al., 2000). Overall results indicate that p53 mutations often occurred in low grade gliomas (WHO grade II astrocytoma; Bourne and Schiff, 2010) and thus is a frequent event in the pathological progression of secondary glioblastoma (WHO Grade IV; Gladson et al., 2010). Secondary glioblastoma arise from a preexisting grade II or III astrocytoma in contrast with primary glioblastoma that form de novo. Primary glioblastoma represent about $90 \%$ of glioblastoma. p53 gene mutations are present in about $30 \%$ of primary glioblastoma, and occur more frequently in secondary glioblastoma (65\%; Ohgaki et al., 2004; Zheng et al., 2008). A recent integrated genomic analysis identified four relevant subclasses of glioblastoma (proneural, mesenchymal, neural, and classical glioblastoma). p53 mutation was observed in 54, 32,21 , and $0 \%$ of tumors from the proneural, mesenchymal, neural, and classical glioblastoma subtype, respectively (Verhaak et al., 2010). Interestingly, classical glioblastoma benefit from more aggressive therapy regimen than the others (Verhaak et al., 2010). In fact, the prognostic value of p53 status may be reconsidered according to these data.

\section{p53 STATUS AND GLIOBLASTOMA PROGNOSIS}

No clear consensus has been reached about the prognostic value of p53 status despite numerous studies (Table 1). A clear picture remains difficult to draw due to the different techniques used to evaluate p53 (including immunostaining on tumor tissues, direct sequencing of p53 gene, and functional assays) and the complexity of patient cohort composition. Data illustrating an association of p53 with survival always point to a longer survival when p53 is mutated (Tada et al., 1998; Schiebe et al., 2000; Birner et al., 2002; Burton et al., 2002). However, the majority of studies do not validate p53 as an independent prognostic marker for glioblastoma (Kraus et al., 2001; Simmons et al., 2001; Shiraishi et al., 2002; Rich et al., 2005; Ruano et al., 2009; Weller et al., 2009; Levidou et al., 2010; Rossi et al., 2011). Overall it means that the prognostic impact of p53 aberrations is only marginal when considered in a global glioblastoma patient population. Reevaluation of this impact in clinically relevant glioblastoma subpopulations (see above) and association with specific molecular signatures will certainly be of interest in the future.

\section{p53 AND GLIOMA-INITIATING STEM CELLS}

Recent studies begin to shed light onto the role of p53 in the regulation of neural stem cells (NSCs). NSCs are self-renewing cells in the central nervous system that can generate both neurons and glia. An elegant study showed that dual inactivation of p53 and PTEN in murine NSC promotes an undifferentiated state with high renewal potential and generates tumors with a high grade glioma phenotype (Zheng et al., 2008). Although the role of p53 in brain tumor stem cells has not been well established, data suggest that loss of differentiation and increase in neurosphere renewal may be linked to the disruption of the p53 pathway in glioma (Molchadsky et al., 2010; Mendrysa et al., 2011; Spike and Wahl, 2011). To achieve a permanent eradication of brain tumors, it is noteworthy that glioma-initiating stem cells have to be considered and in this way their p53 status and functions need to be further explored.

\section{p53 AND TMZ}

Despite expressing mainly a wild-type p53 and thus being expected to be sensitive to DNA-damaging agents, primary glioblastoma resist standard therapies including chemotherapy with TMZ. This intriguing observation is in debate and the role of p53 status 
Table 1 | Evaluation of p53 status in glioblastoma.

\begin{tabular}{|c|c|c|c|c|}
\hline Sequencing/yeast functional assay & 42 & 43 & $\begin{array}{l}\text { YES (longer survival for patients with } \\
\text { p53mut tumors) }\end{array}$ & Tada et al. (1998) \\
\hline Sequencing & 75 & 32 & $\begin{array}{l}\text { YES (longer survival for patients with } \\
\text { p53mut tumors) }\end{array}$ & Schiebe et al. (2000) \\
\hline Sequencing/yeast functional assay & 123 & 31 & NO & Shiraishi et al. (2002) \\
\hline \multirow[t]{2}{*}{ Sequencing/immunostaining } & 41 long-term survivors & 25 & $\begin{array}{l}\text { YES (longer survival for patients with p53 } \\
\text { positive tumors) }\end{array}$ & Burton et al. (2002) \\
\hline & 48 short-term survivors & 31 & & \\
\hline Sequencing/immunostaining & 194 & l & NO & Ruano et al. (2009) \\
\hline Sequencing/immunostaining & 291 & 15 & NO & Weller et al. (2009) \\
\hline Immunostaining & 77 Meta analysis & l & NO & Levidou et al. (2010) \\
\hline Immunostaining & 106 & l & NO & Rossi et al. (2011) \\
\hline
\end{tabular}

in response to $\mathrm{TMZ}$ has been largely addressed in preclinical studies. Conflicting results have been obtained (Table 2) and show either an improved capability of TMZ to inhibit cell viability when p53wt is functionally inhibited (Hirose et al., 2001; Xu et al., 2001, 2005a,b; Dinca et al., 2008; Blough et al., 2011) or a sensitization of cells to drugs when p53wt is functional (Hermisson et al., 2006; Roos et al., 2007). The former studies suggested that glioma cells with an intact p53 gene are selectively impaired in the proapoptotic functions of p53wt while retaining the potential to mediate relevant DNA repair and cell cycle arrest. Treatment with TMZ induced a persistent cell cycle arrest and an increase in p21 (a cell cycle regulator) in functional p53-expressing cells which showed morphological and biochemical features of senescent cells (Hirose et al., 2001; Martinkova et al., 2010). In cells impaired for p53 function or with a mutant p53, TMZ induced a transient cell cycle arrest and cell death via apoptosis or mitotic catastrophe (Hirose et al., 2001; Martinkova et al., 2010) as well as attenuation of DNA repair (Xu et al., 2005b). When TMZ-triggered apoptosis

Table 2 | Role of p53 in TMZ outcome.

\begin{tabular}{|c|c|c|c|}
\hline Material & p53 inhibition & $\begin{array}{l}\text { Effect of p53 modulation on TMZ } \\
\text { sensibility }\end{array}$ & Reference \\
\hline Glioblastoma cell lines (U87MG, LNZ308) & By oncoprotein E6 & Increased sensibility & Hirose et al. (2001) \\
\hline Glioblastoma cell lines (SWB95, SWB77, SWB33, & & p53-independent cell cycle arrest & Bocangel et al. (2002) \\
\hline \multicolumn{4}{|l|}{ SWB40, SWB39, SWB61, D54) xenografts } \\
\hline Glioblastoma cell lines (U87MG, LNZ308) & By pifithrin- $\alpha$ & Increased sensibility & Xu et al. (2005a) \\
\hline Glioblastoma cell lines (D54, A172) & By oncoprotein E6 & Increased sensibility & Xu etal. (2005b) \\
\hline Glioblastoma cell lines (U87MG, U373MG, U251MG, & By siRNA & Decreased sensibility & Hermisson et al. (2006) \\
\hline \multicolumn{4}{|l|}{ U138MG, LN18, LN428, LN319, LNT229, LN308, } \\
\hline \multicolumn{4}{|l|}{ D247MG, T98G) } \\
\hline Glioblastoma cell lines (U87MG, U138MG) & By pifithrin- $\alpha$ & Decreased sensibility & Roos et al. (2007) \\
\hline Glioblastoma cell lines (U87MG) xenografts of biopsies & By pifithrin- $\alpha$ & Increased sensibility & Dinca et al. (2008) \\
\hline Glioblastoma cell lines (U87MG, LNZ308, LN443, SF767, & By siRNA & In cell lines : increased sensibility & Blough etal. (2011) \\
\hline \multicolumn{4}{|l|}{ U251N, U373) } \\
\hline Cancer stem cells & & In stem cells : decreased sensibility & \\
\hline
\end{tabular}


was reported for both p53wt and p53mutant cells, pathways involved differed with activation of the FAS apoptotic pathway or the mitochondrial apoptotic pathway, respectively (Roos et al., 2007). Thus adverse effects of p53wt activities are increasingly recognized and may participate in chemoresistance of diverse cancers including glioma (Kim et al., 2009; Martinez-Rivera and Siddik, 2012). In one recent report, the effect of p53 status on response to TMZ was explored in glioma-initiating stem cells. It was shown that tumor stem cells are resistant to TMZ when p53 is mutated and sensitive to TMZ when intact (Blough et al., 2011). These data add a new level of complexity in the relationship between p53 status and TMZ sensitivity in glioma.

\section{INTEGRINS AND p53}

Although p53 itself is functional in a great majority of primary glioblastoma, inactivation of the p53 signaling pathway occurred in the form of ARF deletions, amplifications of mdm 2 or mdm4 leading to p53 signaling alterations in $87 \%$ of glioblastoma (Network, 2008). Additionally several oncogenes such as the glioma oncoprotein Bcl2L12 (Stegh et al., 2010) were reported to be overexpressed in p53wt tumors and to impair p53 signaling pathway. Few reports investigated the relationship between integrins and p53 signaling pathways. Both integrin-dependent activation (Lewis et al., 2002) and inhibition (Bao and Stromblad, 2004) of p53 signaling have been suggested in different tumoral settings except gliomas. For example, Stromblad and colleagues demonstrated that $\alpha_{V} \beta_{3}$ integrin impacts negatively on p53wt activity in melanoma cells (Bao and Stromblad, 2004; Smith et al., 2012). We proposed recently that $\alpha_{5} \beta_{1}$ integrin plays a similar role in high grade glioma (Janouskova et al., 2012). We demonstrated that overexpression of the $\alpha_{5}$ integrin subunit in p53wt U87MG cells impaired the activation of p53 and its transcriptional activity in response to TMZ. Under such conditions, cells became resistant to this alkylating agent. No such effects were found in p53 mutant glioma cell lines. Interestingly, higher levels of $\alpha_{5}$ integrin were found in p53wt tumor biopsies than in p53 mutant tumor biopsies suggesting a link between this specific integrin and p53 status in vivo. Our in vitro studies also demonstrated that SJ749 and K34c, two specific non-peptidic

\section{REFERENCES}

Alam, N., Goel, H. L., Zarif, M. J., Butterfield, J. E., Perkins, H. M., Sansoucy, B. G., et al. (2007). The integrin-growth factor receptor duet. J. Cell. Physiol. 213, 649-653.

Aoudjit, F., and Vuori, K. (2001a). Integrin signaling inhibits paclitaxelinduced apoptosis in breast cancer cells. Oncogene 20, 4995-5004.

Aoudjit, F., and Vuori, K. (2001b). Matrix attachment regulates Fasinduced apoptosis in endothelial cells: a role for c-flip and implications for anoikis. J. Cell Biol. 152, 633-643.

Aoudjit, F., and Vuori, K. (2012). Integrin signaling in cancer cell survival and chemoresistance. Chemother. Res. Pract. 2012, 283181.
Avraamides, C. J., Garmy-Susini, B., and Varner, J. A. (2008). Integrins in angiogenesis and lymphangiogenesis. Nat. Rev. Cancer 8, 604-617.

Bao, W., and Stromblad, S. (2004). Integrin alphav-mediated inactivation of p53 controls a MEK1-dependent melanoma cell survival pathway in three-dimensional collagen. J. Cell Biol. 167, 745-756.

Bartik, P., Maglott, A., Entlicher, G., Vestweber, D., Takeda, K., Martin, S., et al. (2008). Detection of a hypersialylated betal integrin endogenously expressed in the human astrocytoma cell line A172. Int. J. Oncol. 32, 1021-1031.

Bass, R., and Ellis, V. (2009). Regulation of urokinase receptor function and pericellular proteolysis by the

antagonists of $\alpha_{5} \beta_{1}$ integrin, improved the therapeutic action of TMZ in a p53-dependent way (Martinkova et al., 2010). Molecular pathways involved in the integrin-dependent chemoresistance in p53wt tumors are currently unknown and deserve further studies. Proteins implicated in integrin signaling have been shown to shuttle between the membrane and the nucleus providing a potential mechanism for communication between integrins and p53. In particular FAK, the main kinase activated by integrins, is known to interfere with p53 activity in the nucleus (Lim et al., 2008; Golubovskaya and Cance, 2011). It will also be interesting to discriminate the potential effect of $\alpha_{5} \beta_{1}$ integrin on transcriptional and non-transcriptional functions of p53. Our data are the first to demonstrate relationships between an integrin and the TMZ-dependent activation of p53 in glioma possibly explaining the resistance to TMZ of a subgroup of patients. It is tempting to suggest that inhibition of $\alpha_{5} \beta_{1}$ integrin by specific antagonists might be an adjuvant treatment to standard therapies in patients expressing high level of $\alpha_{5} \beta_{1}$ integrin and p53wt.

\section{CONCLUSION}

Despite few and sometimes conflicting data available both on integrin expression and p53 status as prognostic and/or predictive markers for high grade glioma, a reevaluation of their roles is warranted. Due to the growing knowledge on glioblastoma heterogeneity and subclassification, it becomes reasonable to address these questions more accurately in well defined subpopulations of patients. Key issues need still to be addressed before proposing $\alpha_{5} \beta_{1}$ integrin expression level and p53 status as relevant biomarkers to stratify group of patients which may be more responsive to TMZ.

\section{ACKNOWLEDGMENTS}

We sincerely apologize to those whose work we were unable to discuss due to space limitations. Work in the author's laboratory is supported by the Ligue Contre le Cancer (Comité du Grand Est), by Alsace contre le Cancer, by the Fondation ARC pour le Recherche sur le Cancer. Hana Janouskova is a predoctoral fellow from the French Ministère des Affaires Etrangères and from the Fondation ARC pour la Recherche sur le Cancer.

integrin alpha(5)beta(1). Thromb. Haemost. 101, 954-962.

Birner, P., Piribauer, M., Fischer, I., Gatterbauer, B., Marosi, C., Ungersbock, K., et al. (2002). Prognostic relevance of $\mathrm{p} 53$ protein expression in glioblastoma. Oncol. Rep. 9, 703-707. Blough, M. D., Beauchamp, D. C., Westgate, M. R., Kelly, J. J., and Cairncross, J. G. (2011). Effect of aberrant p53 function on temozolomide sensitivity of glioma cell lines and brain tumor initiating cells from glioblastoma. $J$. Neurooncol. 102, 1-7.

Bocangel, D. B., Finkelstein, S., Schold, S. C., Bhakat, K. K., Mitra, S. and Kokkinakis, D. M. (2002). Multifaceted resistance of gliomas to temozolomide. Clin. Cancer Res. 8, 2725-2734.
Bourne, T. D., and Schiff, D. (2010). Update on molecular findings, management and outcome in lowgrade gliomas. Nat. Rev. Neurol. 6, 695-701.

Bredel, M., Bredel, C., Juric, D., Harsh, G. R., Vogel, H., Recht, L. D., et al. (2005). Functional network analysis reveals extended gliomagenesis pathway maps and three novel MYC-interacting genes in human gliomas. Cancer Res. 65, 8679-8689.

Brooks, P. C., Stromblad, S., Klemke, R., Visscher, D., Sarkar, F. H., and Cheresh, D. A. (1995). Antiintegrin alpha $\mathrm{v}$ beta 3 blocks human breast cancer growth and angiogenesis in human skin. J. Clin. Invest. 96, 18151822 . 
Burton, E. C., Lamborn, K. R., Forsyth, P., Scott, J., O'Campo, J., Uyehara-Lock, J., et al. (2002). Aberrant p53, mdm2, and proliferation differ in glioblastomas from long-term compared with typical survivors. Clin. Cancer Res. 8, 180-187.

Bussolati, B., Deambrosis, I., Russo, S., Deregibus, M. C., and Camussi, G. (2003). Altered angiogenesis and survival in human tumor-derived endothelial cells. FASEB J. 17, 11591161.

Carlson, B. L., Grogan, P. T., Mladek, A. C., Schroeder, M. A., Kitange, G. J., Decker, P. A., et al. (2009). Radiosensitizing effects of temozolomide observed in vivo only in a subset of O6-methylguanine-DNA methyltransferase methylated glioblastoma multiforme xenografts. Int. J. Radiat. Oncol. Biol. Phys. 75, 212-219.

Carlson, T. R., Feng, Y., Maisonpierre, P. C., Mrksich, M., and Morla, A. O. (2001). Direct cell adhesion to the angiopoietins mediated by integrins. J. Biol. Chem. 276, 26516-26525.

Chamberlain, M. C., Cloughsey, T., Reardon, D. A., and Wen, P. Y. (2012). A novel treatment for glioblastoma: integrin inhibition. Expert Rev. Neurother. 12, 421-435.

Colin, C., Baeza, N., Bartoli, C., Fina, F., Eudes, N., Nanni, I., et al. (2006). Identification of genes differentially expressed in glioblastoma versus pilocytic astrocytoma using Suppression Subtractive Hybridization. Oncogene 25, 2818-2826.

Combs, S. E., Rieken, S., Wick, W., Abdollahi, A., von Deimling, A. Debus, J., et al. (2011). Prognostic significance of IDH-1 and MGMT in patients with glioblastoma: one step forward, and one step back? Radiat. Oncol. 6, 115.

Cordes, N., Seidler, J., Durzok, R., Geinitz, H., and Brakebusch, C. (2006). betal-integrin-mediated signaling essentially contributes to cell survival after radiation-induced genotoxic injury. Oncogene 25, 1378 1390.

Cosset, E. C., Godet, J., Entz-Werlé, N., Guerin, E., Guenot, D., Froelich, S., et al. (2012). Involvement of TGF $\beta$ pathway in the regulation of $\alpha 5 \beta 1$ integrins by caveolin-1 in human glioblastoma. Int. J. Cancer. 131, 601-611.

Courter, D. L., Lomas, L., Scatena, M., and Giachelli, C. M. (2005). Src kinase activity is required for integrin alphaVbeta3-mediated activation of nuclear factor-kappaB. J. Biol. Chem. 280, 12145-12151.

D’Abaco, G. M., and Kaye, A. H. (2007). Integrins: molecular determinants of glioma invasion. J. Clin. Neurosci. 14, 1041-1048.

Dai, C., and Gu, W. (2010). p53 post-translational modification: deregulated in tumorigenesis. Trends Mol. Med. 16, 528-536.

Delamarre, E., Taboubi, S., Mathieu, S., Berenguer, C., Rigot, V., Lissitzky, J. C., et al. (2009). Expression of integrin alpha6betal enhances tumorigenesis in glioma cells. Am. J. Pathol. 175, 844-855.

DeLay, M., Jahangiri, A., Carbonell, W. S., Hu, Y. L., Tsao, S., Tom, M. W., et al. (2012). Microarray analysis verifies two distinct phenotypes of glioblastomas resistant to antiangiogenic therapy. Clin. Cancer Res. 18, 2930-2942.

Desgrosellier, J. S., Barnes, L. A., Shields, D. J., Huang, M., Lau, S. K., Prevost, N., et al. (2009). An integrin alpha(v)beta(3)-c-Src oncogenic unit promotes anchorage-independence and tumor progression. Nat. Med. 15, 1163-1169.

Desgrosellier, J. S., and Cheresh, D. A. (2010). Integrins in cancer: biological implications and therapeutic opportunities. Nat. Rev. Cancer 10 9-22.

Dinca, E. B., Lu, K. V., Sarkaria, J. N., Pieper, R. O., Prados, M. D., Haas-Kogan, D. A., etal. (2008). p53 Small-molecule inhibitor enhances temozolomide cytotoxic activity against intracranial glioblastoma xenografts. Cancer Res. 68 10034-10039.

Eliceiri, B. P. (2001). Integrin and growth factor receptor crosstalk. Circ. Res. 89, 1104-1110.

Figarella-Branger, D., Maues de Paula, A., Colin, C., and Bouvier, C. (2011). Histomolecular classification of adult diffuse gliomas: the diagnostic value of immunohistochemical markers. Rev. Neurol. (Paris) 167, 683-690.

Fournier, A. K., Campbell, L. E., Castagnino, P., Liu, W. F., Chung, B. M., Weaver, V. M., et al. (2008). Racdependent cyclin D1 gene expression regulated by cadherin- and integrinmediated adhesion. J. Cell Sci. 121, 226-233.

Freije, W. A., Castro-Vargas, F. E., Fang, Z., Horvath, S., Cloughesy, T., Liau, L. M., et al. (2004). Gene expression profiling of gliomas strongly predicts survival. Cancer Res. 64, 6503-6510.

Friedlander, D. R., Zagzag, D., Shiff, B., Cohen, H., Allen, J. C., Kelly, P. J., et al. (1996). Migration of brain tumor cells on extracellular matrix proteins in vitro correlates with tumor type and grade and involves alphaV and betal integrins. Cancer Res. 56, 1939 1947.

Friedlander, M., Brooks, P. C., Shaffer, R. W., Kincaid, C. M., Varner, J. A. and Cheresh, D. A. (1995). Definition of two angiogenic pathways by distinct alpha v integrins. Science 270 , 1500-1502.

Fulci, G., Labuhn, M., Maier, D., Lachat, Y., Hausmann, O., Hegi, M. E., et al. (2000). p53 gene mutation and ink4a-arf deletion appear to be two mutually exclusive events in human glioblastoma. Oncogene 19, 3816-3822.

Geiger, B., Bershadsky, A., Pankov, R., and Yamada, K. M. (2001). Transmembrane crosstalk between the extracellular matrix-cytoskeleton crosstalk. Nat. Rev. Mol. Cell Biol. 2, 793-805.

Ghosh, S., Brown, R., Jones, J. C. Ellerbroek, S. M., and Stack, M S. (2000). Urinary-type plasminogen activator ( $\mathrm{uPA}$ ) expression and $\mathrm{uPA}$ receptor localization are regulated by alpha 3beta 1 integrin in oral keratinocytes. J. Biol. Chem. 275, 23869-23876.

Gingras, M. C., Roussel, E., Bruner, J. M., Branch, C. D., and Moser, R. P. (1995). Comparison of cell adhesion molecule expression between glioblastoma multiforme and autologous normal brain tissue. J. Neuroimmunol. 57, 143-153.

Gladson, C. L., and Cheresh, D. A. (1991). Glioblastoma expression of vitronectin and the alpha $\mathrm{v}$ beta 3 integrin. Adhesion mechanism for transformed glial cells. J. Clin. Invest. 88, 1924-1932.

Gladson, C. L., Prayson, R. A., and Liu, W. M. (2010). The pathobiology of glioma tumors. Annu. Rev. Pathol. 5, 33-50.

Golubovskaya, V. M., and Cance, W. G. (2011). FAK and p53 Protein Interactions. Anticancer Agents Med. Chem. 11, 617-619.

Goodman, S. L., and Picard, M. (2012). Integrins as therapeutic targets. Trends Pharmacol. Sci. 33, 405-412.

Gritsenko, P. G., Ilina, O., and Friedl, P. (2012). Interstitial guidance of cancer invasion. J. Pathol. 226, 185-199.

Hegi, M. E., Diserens, A. C., Gorlia, T., Hamou, M. F., de Tribolet, N., Weller, M., et al. (2005). MGMT gene silencing and benefit from temozolomide in glioblastoma. N. Engl. J. Med. 352, 997-1003.

Hermisson, M., Klumpp, A., Wick, W., Wischhusen, J., Nagel, G., Roos, W., et al. (2006). O6-methylguanine DNA methyltransferase and p53 status predict temozolomide sensitivity in human malignant glioma cells. $J$ Neurochem. 96, 766-776.

Hikawa, T., Mori, T., Abe, T., and Hori, S. (2000). The ability in adhesion and invasion of drug-resistant human glioma cells. J. Exp. Clin. Cancer Res. 19, 357-362.

Hirose, Y., Berger, M. S., and Pieper, R. O. (2001). p53 effects both the duration of $\mathrm{G} 2 / \mathrm{M}$ arrest and the fate of temozolomide-treated human glioblastoma cells. Cancer Res. 61, 1957-1963.

Hodivala-Dilke, K. (2008). alphavbeta3 integrin and angiogenesis: a moody integrin in a changing environment. Curr. Opin. Cell Biol. 20, 514-519.

Holmes, K. M., Annala, M., Chua, C. Y., Dunlap, S. M., Liu, Y., Hugen, N., et al. (2012). Insulinlike growth factor-binding protein 2-driven glioma progression is prevented by blocking a clinically significant integrin, integrin-linked kinase, and NF-kappaB network. Proc. Natl. Acad. Sci. U.S.A. 109, 3475-3480.

Hutchings, H., Ortega, N., and Plouet, J. (2003). Extracellular matrix-bound vascular endothelial growth factor promotes endothelial cell adhesion, migration, and survival through integrin ligation. FASEB J. 17, 1520-1522.

Hynes, R. O. (2002). Integrins: bidirectional, allosteric signaling machines. Cell 110, 673-687.

Jan, Y., Matter, M., Pai, J. T., Chen, Y. L., Pilch, J., Komatsu, M., et al. (2004). A mitochondrial protein, Bit1, mediates apoptosis regulated by integrins and Groucho/TLE corepressors. Cell $116,751-762$.

Janouskova, H., Maglott, A., Leger, D. Y., Bossert, C., Noulet, F., Guerin, E., et al. (2012). Integrin $\alpha 5 \beta 1$ plays a critical role in resistance to temozolomide by interfering with the p53 pathway in high grade glioma. Cancer Res. 72, 3463-3470.

Kanamori, M., Kawaguchi, T., Berger, M. S., and Pieper, R. O. (2006). Intracranial microenvironment reveals independent opposing functions of host alphaVbeta3 expression on glioma growth and angiogenesis. J. Biol. Chem. 281, 3725637264.

Kanamori, M., Vanden Berg, S. R., Bergers, G., Berger, M. S., and Pieper, R. O. (2004). Integrin beta3 overexpression suppresses tumor growth in a human model of gliomagenesis: implications for the role of beta3 overexpression in glioblastoma multiforme. Cancer Res. 64, 2751-2758.

Kawataki, T., Yamane, T., Naganuma, H., Rousselle, P., Anduren, I., Tryggvason, K., et al. (2007). Laminin 
isoforms and their integrin receptors in glioma cell migration and invasiveness: evidence for a role of alpha5laminin(s) and alpha3betal integrin. Exp. Cell Res. 313, 3819-3831.

Kim, E., Giese, A., and Deppert, W. (2009). Wild-type p53 in cancer cells: when a guardian turns into a blackguard. Biochem. Pharmacol. 77, 1120.

Kim, S., Bell, K., Mousa, S. A., and Varner, J. A. (2000). Regulation of angiogenesis in vivo by ligation of integrin alpha5betal with the central cell-binding domain of fibronectin. Am. J. Pathol. 156, 1345-1362.

Kita, D., Takino, T., Nakada, M., Takahashi, T., Yamashita, J., and Sato, H. (2001). Expression of dominant-negative form of Ets1 suppresses fibronectin-stimulated cell adhesion and migration through down-regulation of integrin alpha5 expression in U251 glioma cell line. Cancer Res. 61, 7985-7991.

Kraus, J. A., Wenghoefer, M., Glesmann, N., Mohr, S., Beck, M., Schmidt, M. C., et al. (2001). TP53 gene mutations, nuclear p53 accumulation, expression of Waf/p21, Bcl-2, and CD95 (APO-1/Fas) proteins are not prognostic factors in de novo glioblastoma multiforme. $J$. Neurooncol. 52, 263-272.

Lamar, J. M., Pumiglia, K. M., and DiPersio, C. M. (2008). An immortalization-dependent switch in integrin function up-regulates MMP-9 to enhance tumor cell invasion. Cancer Res. 68, 7371-7379.

Lathia, J. D., Gallagher, J., Heddleston, J. M., Wang, J., Eyler, C. E., Macswords, J., et al. (2010). Integrin alpha 6 regulates glioblastoma stem cells. Cell Stem Cell 6, 421-432.

Lathia, J. D., Gallagher, J., Myers, J. T., Li, M., Vasanji, A., McLendon, R. E., et al. (2011). Direct in vivo evidence for tumor propagation by glioblastoma cancer stem cells. PLoS ONE 6, e24807. doi: 10.1371/journal.pone. 0024807

Legate, K. R., Wickstrom, S. A., and Fassler, R. (2009). Genetic and cell biological analysis of integrin outside-in signaling. Genes Dev. 23, 397-418.

Levidou, G., El-Habr, E., Saetta, A. A., Bamias, C., Katsouyanni, K., Patsouris, E., et al. (2010). P53 immunoexpression as a prognostic marker for human astrocytomas: a metaanalysis and review of the literature. J. Neurooncol. 100, 363-371.

Levine, A. J., and Oren, M. (2009). The first 30 years of p53: growing ever more complex. Nat. Rev. Cancer 9, 749-758.
Lewis, J. M., Truong, T. N., and Schwartz, M. A. (2002). Integrins regulate the apoptotic response to DNA damage through modulation of p53. Proc. Natl. Acad. Sci. U.S.A. 99, 3627-3632.

Lim, S. T., Chen, X. L., Lim, Y., Hanson, D. A., Vo, T. T., Howerton, K., et al. (2008). Nuclear FAK promotes cell proliferation and survival through FERM-enhanced p53 degradation. Mol. Cell 29, 9-22.

Maglott, A., Bartik, P., Cosgun, S., Klotz, P., Ronde, P., Fuhrmann, G., et al. (2006). The small alpha5betal integrin antagonist, SJ749, reduces proliferation and clonogenicity of human astrocytoma cells. Cancer Res. 66, 6002-6007.

Magnussen, A., Kasman, I. M., Norberg, S., Baluk, P., Murray, R., and McDonald, D. M. (2005). Rapid access of antibodies to alpha5betal integrin overexpressed on the luminal surface of tumor blood vessels. Cancer Res. 65, 2712-2721.

Mahesparan, R., Read, T. A., LundJohansen, M., Skaftnesmo, K. O., Bjerkvig, R., and Engebraaten, O. (2003). Expression of extracellular matrix components in a highly infiltrative in vivo glioma model. Acta Neuropathol. 105, 49-57.

Martin, S., Cosset, E. C., Terrand, J., Maglott, A., Takeda, K., and Dontenwill, M. (2009). Caveolin1 regulates glioblastoma aggressiveness through the control of alpha(5)beta(1) integrin expression and modulates glioblastoma responsiveness to SJ749, an alpha(5)beta(1) integrin antagonist. Biochim. Biophys. Acta 1793, 354-367.

Martinez-Rivera, M., and Siddik, Z. H. (2012). Resistance and gainof-resistance phenotypes in cancers harboring wild-type p53. Biochem. Pharmacol. 83, 1049-1062.

Martinkova, E., Maglott, A., Leger, D. Y., Bonnet, D., Stiborova, M., Takeda, K., et al. (2010). alpha5betal integrin antagonists reduce chemotherapyinduced premature senescence and facilitate apoptosis in human glioblastoma cells. Int. J. Cancer 127, 1240-1248.

Matter, M. L., and Ruoslahti, E. (2001). A signaling pathway from the alpha5betal and alpha(v)beta3 integrins that elevates bcl-2 transcription. J. Biol. Chem. 276, 2775727763.

Mattern, R. H., Read, S. B., Pierschbacher, M. D., Sze, C. I., Eliceiri, B. P., and Kruse, C. A. (2005). Glioma cell integrin expression and their interactions with integrin antagonists. Cancer Ther. 3A, 325-340.
Mendrysa, S. M., Ghassemifar, S., and Malek, R. (2011). p53 in the CNS: perspectives on development, stem cells, and cancer. Genes Cancer 2, 431-442.

Mettouchi, A., and Meneguzzi, G. (2006). Distinct roles of betal integrins during angiogenesis. Eur. J. Cell Biol. 85, 243-247.

Molchadsky, A., Rivlin, N., Brosh, R., Rotter, V., and Sarig, R. (2010). p53 is balancing development, differentiation and de-differentiation to assure cancer prevention. Carcinogenesis 31 , 1501-1508.

Monferran, S., Skuli, N., Delmas, C., Favre, G., Bonnet, J., CohenJonathan-Moyal, E., et al. (2008). Alphavbeta3 and alphavbeta5 integrins control glioma cell response to ionising radiation through ILK and RhoB. Int. J. Cancer 123, 357-364.

Morozevich, G., Kozlova, N., Cheglakov, I., Ushakova, N., and Berman, A. (2009). Integrin alpha5beta1 controls invasion of human breast carcinoma cells by direct and indirect modulation of MMP-2 collagenase activity. Cell Cycle 8, 2219-2225.

Network, C. G. A. R. (2008). Comprehensive genomic characterization defines human glioblastoma genes and core pathways. Nature 455, 10611068.

Ohgaki, H., Dessen, P., Jourde, B., Horstmann, S., Nishikawa, T. Di Patre, P. L., et al. (2004). Genetic pathways to glioblastoma: a population-based study. Cancer Res. 64, 6892-6899.

Paulus, W., Baur, I., Beutler, A. S., and Reeves, S. A. (1996). Diffuse brain invasion of glioma cells requires beta 1 integrins. Lab. Invest. 75 819-826.

Reynolds, L. E., Wyder, L., Lively, J. C., Taverna, D., Robinson, S. D., Huang, X., et al. (2002). Enhanced pathological angiogenesis in mice lacking beta3 integrin or beta 3 and beta 5 integrins. Nat. Med. 8, 27-34.

Rich, J. N., Hans, C., Jones, B., Iversen, E. S., McLendon, R. E., Rasheed, B. K., etal. (2005). Gene expression profiling and genetic markers in glioblastoma survival. Cancer Res. 65, 4051-4058.

Riemenschneider, M. J., Mueller, W. Betensky, R. A., Mohapatra, G. and Louis, D. N. (2005). In situ analysis of integrin and growth factor receptor signaling pathways in human glioblastomas suggests overlapping relationships with focal adhesion kinase activation. Am. J. Pathol. 167, 1379-1387.
Robinson, S. D., and Hodivala-Dilke, K. M. (2011). The role of beta3integrins in tumor angiogenesis: context is everything. Curr. Opin. Cell Biol. 23, 630-637.

Roos, W. P., Batista, L. F., Naumann, S. C., Wick, W., Weller, M., Menck, C. F., et al. (2007). Apoptosis in malignant glioma cells triggered by the temozolomide-induced DNA lesion O6-methylguanine. Oncogene 26, 186-197.

Rossi, M., Magnoni, L., Miracco, C., Mori, E., Tosi, P., Pirtoli, L., et al. (2011). beta-catenin and Gli1 are prognostic markers in glioblastoma. Cancer Biol. Ther. 11, 753-761.

Ruano, Y., Ribalta, T., de Lope, A. R., Campos-Martin, Y., Fiano, C., Perez-Magan, E., et al. (2009). Worse outcome in primary glioblastoma multiforme with concurrent epidermal growth factor receptor and p53 alteration. Am. J. Clin. Pathol. 131, 257-263.

Scatena, M., and Giachelli, C. (2002). The alpha(v)beta3 integrin, NFkappaB, osteoprotegerin endothelial cell survival pathway. Potential role in angiogenesis. Trends Cardiovasc. Med. 12, 83-88.

Schiebe, M., Ohneseit, P., Hoffmann, W., Meyermann, R., Rodemann, H. P., and Bamberg, M. (2000). Analysis of $\mathrm{mdm} 2$ and $\mathrm{p} 53$ gene alterations in glioblastomas and its correlation with clinical factors. J. Neurooncol. 49, 197-203.

Schnell, O., Krebs, B., Wagner, E., Romagna, A., Beer, A. J., Grau, S. J., et al. (2008). Expression of integrin alphavbeta3 in gliomas correlates with tumor grade and is not restricted to tumor vasculature. Brain Pathol. 18, 378-386.

Shiraishi, S., Tada, K., Nakamura, H., Makino, K., Kochi, M., Saya, H., et al. (2002). Influence of p53 mutations on prognosis of patients with glioblastoma. Cancer 95, 249-257.

Silber, J. R., Bobola, M. S., Blank, A., and Chamberlain, M. C. (2012). O(6)-Methylguanine-DNA methyltransferase in glioma therapy: promise and problems. Biochim. Biophys. Acta 1826, 71-82.

Simmons, M. L., Lamborn, K. R., Takahashi, M., Chen, P., Israel, M. A., Berger, M. S., et al. (2001). Analysis of complex relationships between age, p53, epidermal growth factor receptor, and survival in glioblastoma patients. Cancer Res. 61, 1122-1128.

Skuli, N., Monferran, S., Delmas, C., Favre, G., Bonnet, J., Toulas, C., et al. (2009). Alphavbeta3/alphavbeta5 integrinsFAK-RhoB: a novel pathway for 
hypoxia regulation in glioblastoma. Cancer Res. 69, 3308-3316.

Smith, S. D., Enge, M., Bao, W., Thullberg, M., Costa, T. D., Olofsson, H., etal. (2012). Protein Kinase C alpha (PKCalpha) regulates p53 localisation and melanoma cell survival downstream of integrin alphav in 3Dcollagen and in vivo. J. Biol. Chem. 287, 29336-29347.

Soung, Y. H., Clifford, J. L., and Chung, J. (2010). Crosstalk between integrin and receptor tyrosine kinase signaling in breast carcinoma progression. BMB Rep. 43, 311-318.

Speidel, D. (2010). Transcriptionindependent p53 apoptosis: an alternative route to death. Trends Cell Biol. 20, 14-24.

Spike, B. T., and Wahl, G. M. (2011). p53, stem cells, and reprogramming: tumor suppression beyond guarding the genome. Genes Cancer 2, 404419.

Stegh, A. H., Brennan, C., Mahoney, J. A., Forloney, K. L., Jenq, H. T., Luciano, J. P., et al. (2010). Glioma oncoprotein $\mathrm{Bcl} 2 \mathrm{~L} 12$ inhibits the p53 tumor suppressor. Genes Dev. 24, 2194-2204.

Stupack, D. G., Puente, X. S., Boutsaboualoy, S., Storgard, C. M., and Cheresh, D. A. (2001). Apoptosis of adherent cells by recruitment of caspase- 8 to unligated integrins. $J$. Cell Biol. 155, 459-470.

Stupp, R., Hegi, M. E., Mason, W. P., van den Bent, M. J., Taphoorn, M. J., Janzer, R. C., et al. (2009). Effects of radiotherapy with concomitant and adjuvant temozolomide versus radiotherapy alone on survival in glioblastoma in a randomised phase III study: 5-year analysis of the EORTC-NCIC trial. Lancet Oncol. 10, 459-466.

Stupp, R., Hegi, M. E., Neyns, B., Goldbrunner, R., Schlegel, U., Clement,
P. M., et al. (2010). Phase I/IIa study of cilengitide and temozolomide with concomitant radiotherapy followed by cilengitide and temozolomide maintenance therapy in patients with newly diagnosed glioblastoma. J. Clin. Oncol. 28, 2712-2718.

Stupp, R., Mason, W. P., van den Bent, M. J., Weller, M., Fisher, B., Taphoorn, M. J., et al. (2005). Radiotherapy plus concomitant and adjuvant temozolomide for glioblastoma. N. Engl. J. Med. 352, 987-996.

Sullivan, K. D., Gallant-Behm, C. L. Henry, R. E., Fraikin, J. L., and Espinosa, J. M. (2012). The p53 circuit board. Biochim. Biophys. Acta 1825, 229-244.

Tabatabai, G., Weller, M., Nabors, B., Picard, M., Reardon, D., Mikkelsen, T., et al. (2010). Targeting integrins in malignant glioma. Target Oncol. 5, 175-181.

Tada, M., Iggo, R. D., Waridel, F., Nozaki, M., Matsumoto, R., Sawamura, Y., et al. (1997). Reappraisal of p53 mutations in human malignant astrocytic neoplasms by p53 functional assay: comparison with conventional structural analyses. Mol. Carcinog. 18, 171-176.

Tada, M., Matsumoto, R., Iggo, R. D. Onimaru, R., Shirato, H., Sawamura Y., et al. (1998). Selective sensitivity to radiation of cerebral glioblastomas harboring 553 mutations. Cancer Res. 58, 1793-1797.

Tso, C. L., Freije, W. A., Day, A. Chen, Z., Merriman, B., Perlina, A., et al. (2006). Distinct transcription profiles of primary and secondary glioblastoma subgroups. Cancer Res. 66, 159-167.

Tysnes, B. B., Larsen, L. F., Ness, G. O., Mahesparan, R., Edvardsen, K., Garcia-Cabrera, I., et al. (1996). Stimulation of glioma-cell migration by laminin and inhibition by antialpha3 and anti-betal integrin antibodies. Int. J. Cancer 67, 777-784.

Uhm, J. H., Dooley, N. P., Kyritsis, A. P., Rao, J. S., and Gladson, C. L. (1999). Vitronectin, a glioma-derived extracellular matrix protein, protects tumor cells from apoptotic death. Clin. Cancer Res. 5, 1587-1594.

Verhaak, R. G., Hoadley, K. A., Purdom, E., Wang, V., Qi, Y., Wilkerson, M. D., et al. (2010). Integrated genomic analysis identifies clinically relevant subtypes of glioblastoma characterized by abnormalities in PDGFRA IDH1, EGFR, and NF1. Cancer Cell 17, 98-110.

Vousden, K. H., and Prives, C. (2009) Blinded by the light: the growing complexity of p53. Cell 137, 413-431.

Wei, Y., Tang, C. H., Kim, Y., Robillard, L., Zhang, F., Kugler, M. C., et al. (2007). Urokinase receptors are required for alpha 5 beta 1 integrinmediated signaling in tumor cells. $J$. Biol. Chem. 282, 3929-3939.

Weller, M., Felsberg, J., Hartmann, C., Berger, H., Steinbach, J. P., Schramm, J., et al. (2009). Molecular predictors of progression-free and overall survival in patients with newly diagnosed glioblastoma: a prospective translational study of the German Glioma Network. J. Clin. Oncol. 27, 5743-5750.

Wild-Bode, C., Weller, M., and Wick, W. (2001). Molecular determinants of glioma cell migration and invasion. J. Neurosurg. 94, 978-984.

Xu, G. W., Mymryk, J. S., and Cairncross, J. G. (2005a). Inactivation of p53 sensitizes astrocytic glioma cells to BCNU and temozolomide, but not cisplatin. J. Neurooncol. 74 141-149.

Xu, G. W., Mymryk, J. S., and Cairncross, J. G. (2005b).
Pharmaceutical-mediated inactivation of p53 sensitizes U87MG glioma cells to BCNU and temozolomide. Int. J. Cancer 116, 187-192.

Xu, G. W., Nutt, C. L., Zlatescu, M. C., Keeney, M., Chin-Yee, I., and Cairncross, J. G. (2001). Inactivation of p53 sensitizes U87MG glioma cells to 1 , 3-bis(2-chloroethyl)-1-nitrosourea. Cancer Res. 61, 4155-4159.

Zheng, H., Ying, H., Yan, H., Kimmelman, A. C., Hiller, D. J., Chen, A. J., etal. (2008). p53 and Pten control neural and glioma stem/progenitor cell renewal and differentiation. Nature 455, 1129-1133.

Conflict of Interest Statement: The authors declare that the research was conducted in the absence of any commercial or financial relationships that could be construed as a potential conflict of interest.

Received: 06 September 2012; paper pending published: 18 September 2012; accepted: 16 October 2012; published online: 31 October 2012.

Citation: Martin S, Janouskova $H$ and Dontenwill $M$ (2012) Integrins and p53 pathways in glioblastoma resistance to temozolomide. Front. Oncol. 2:157. doi: 10.3389/fonc.2012.00157

This article was submitted to Frontiers in Radiation Oncology, a specialty of Frontiers in Oncology.

Copyright (c) 2012 Martin, Janouskova and Dontenwill. This is an open-access article distributed under the terms of the Creative Commons Attribution License, which permits use, distribution and reproduction in other forums, provided the original authors and source are credited and subject to any copyright notices concerning any third-party graphics etc. 